\title{
Design \& Static Analysis of Front Rear Axle Crown Wheel of Tourus Model Tipper
}

\author{
Authors \\ A V Hari Babu ${ }^{1}$, Dr B Durga Prasad ${ }^{2}$ \\ *Corresponding Author: \\ A V Hari Babu' ${ }^{1}$ \\ ${ }^{1}$ Associate Professor \& PhD Scholar, AVR\&SVR College of Engg \& Tech., Nandyal. \\ ${ }^{2}$ Professor \& Head of ME Dept, JNTU College of Engineering, Anantapuram \\ Email-av.haribabu@gmail.com,mukdhad@sify.com
}

\begin{abstract}
ABSRTRACT
Present days everybody should move from one place to another place by using an automobile. In an automobile motion is transferred from engine to rear wheel through various mechanical links. In general differential gear box plays an important role in the automobile for transferring motion from engine to rear axle. In general single differential gear box is used for light weight vehicles but heavy load vehicles two or more rear axles with differentials are used for transmitting maximum amount of power from engine to rear axles. So the present paper is focused on the mechanical design and analysis of double axle differential gear box of front rear axle as it transmits the power. This work develops a view to get familiar with the technologies as well as application of theories into practical work done by industries. My research contains the design with the help of CATIA/HYPER MESH and material selection of the double axel differential based on strength and stiffness. For better efficiency, improvement of power transmission rate is an important phenomenon.

In the present work, it is proposed to find the effect of deformation, strength variations in the front Rear differential crown wheel by static analysis of Ashok Leyland tipper (Taurus 2516/2 model) design on the predicted stress by using ABAQUS Software. By identifying the true design features, the extended service life and long term stability can be assured.

Key words: Front rear Differential, CATIA, HYPERMESH and ABAQUS
\end{abstract}

\section{INTRODUCTION}

When a vehicle takes a turn either left or right, the outer wheels must travel more distance than the inner wheels. In an automobile the front wheels can rotate freely on their front axle. However both rear wheels are driven by the engine through gearing. Therefore some sort of automatic device is necessary so that two rear wheels are driven at slightly different speeds.

\section{Constructional details:}

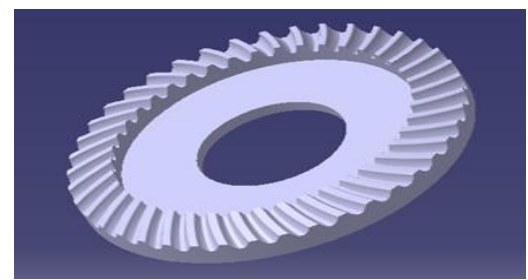

\section{WHY DO YOU NEED A DIFFERENTIAL}

You would not need a differential in your car would always be travelling over a straight line. Unfortunately, driving such a car has certain difficulties - like having to go around the world to return where you started from.

When you need to turn, then you have to address the issue that left and right wheels will have to rotate at a different speed. The difference between the paths travelled by the left (outside) and the right (inside) wheels will be $2 \pi(\mathrm{R}-\mathrm{r})$.

Since both sets of wheels travel over this distance at the same time, the speed differential between the left (outside) and right (inside) wheels is 
Selection of particular model. (Taurus 2516/2 (6x4))

Ashok layland have been different models but this $\mathrm{Ph} \mathrm{D}$ work is related to model Taurus 2516/2(6x4) the detail specification and materials used in this model is as follows

\section{Materials used in gear manufacturing process}

The various materials used for gears include a wide variety of cast irons, non ferrous material and nonmetallic materials the selection of the gear material depends upon i) type of service ii) peripheral speed iii) degree of accuracy required iv) method of manufacture v) required dimensions and weight of the drive vi) allowable stress vii) shock resistance viii) wear resistance.

1. Cast iron is popular due to its good wearing properties, excellent machinability and ease of producing complicated shapes by the casting method. It is suitable where large gears of complicated shapes are needed.

2. Steel is sufficiently strong and highly resistant to wear by abrasion

3. Cast steel is used where stress on gear is high and it is difficult to fabricate the gears

4. Plain carbon steels find application for industrial gears where high toughness combined with high strength

5. Alloy steels are used where high tooth strength and low tooth wear are required

6. Aluminum is used where low inertia of rotating mass is desired

7. Gears made of non-metallic materials give noiseless operation at high peripheral speeds.

In the model Taurus 2516/2 Ashok Leyland the front rear axle differential gear box should be made up of steel G45 Material and their design specifications

\begin{tabular}{|l|l|l|}
\hline & Pinion $(\mathbf{m m})$ & Gear $(\mathbf{m m})$ \\
\hline Pitch cone diameter & $\mathrm{D}_{\mathrm{p}}=60 \mathrm{~mm}$ & $\mathrm{D}_{\mathrm{g}}=210 \mathrm{~mm}$ \\
\hline No. of teeth & $\mathrm{T}_{\mathrm{P}}=7$ & $\mathrm{~T}_{\mathrm{G}}=41$ \\
\hline Module & $\mathrm{M}=5 \mathrm{~mm}$ & $\mathrm{M}=5 \mathrm{~mm}$ \\
\hline Pitch angle & $\theta_{\mathrm{p}}=13.299^{0}$ & $\theta_{\mathrm{g}}=76.7^{0}$ \\
\hline Cone distance & $\mathrm{A}_{0}=55 \mathrm{~mm}$ & $\mathrm{~A}_{0}=55 \mathrm{~mm}$ \\
\hline Face width & $\mathrm{b}=60$ & $\mathrm{~b}=60$ \\
\hline Addendum & $\mathrm{ha}=\mathrm{M}=8 \mathrm{~mm}$ & $\mathrm{Ha}=\mathrm{M}=8 \mathrm{~mm}$ \\
\hline Deddendum & $\mathrm{hd}=1.26 \mathrm{M}=10 \mathrm{~mm}$ & $\mathrm{Hd}=1.2 \mathrm{M}=10 \mathrm{~mm}$ \\
\hline Clearance & $\mathrm{C}=0.2 \mathrm{M}=2 \mathrm{~mm}$ & $\mathrm{C}=0.2 \mathrm{M}=2 \mathrm{~mm}$ \\
\hline
\end{tabular}

\section{HOW TO DESIGN:}

Here to make such a model using PROE or CATIA Software only. While generating the model the designer should keep in mind there are no specific dimensions. All the dimensions should be chosen by the company designers according to their own choice. Then analysis will do by using ANSYS/CATIA soft ware by meshing using HYPERMESH Software

\section{Introduction to ProE/CATIA}

Pro/ENGINEER/CATIA is a feature based, parametric solid/Wireframe modeling program. As such, its use is significantly different from conventional drafting programs. In conventional drafting (either manual or computer assisted), various views of a part are created in an attempt to describe the geometry. Each view incorporates aspects of various features (surfaces, cuts, radii, holes, protrusions) but the features are not individually defined. In feature based modeling, each feature is individually described then 
integrated into the part. The other significant aspect of conventional drafting is that the part geometry is defined by the drawing. If it is desired to change the size, shape, or location of a feature, the physical lines on the drawing must be changed (in each affected view) then associated dimensions are updated. When using parametric modeling, the features are driven by the dimensions (parameters). To modify the diameter of a hole, the whole diameter parameter value is changed. This automatically modifies the feature wherever it occurs - drawing views, assemblies, etc. Another unique attribute of Pro/E or CATIA is that it is a solid modeling program. The design procedure is to create a model, view it, assemble parts as required, then generate any drawings which are required. It should be noted that for many uses of Pro/E or CATIA, complete drawings are never created. A typical design cycle for a molded plastic part might consist of the creation of a solid model, export of an SLA file to a rapid prototyping system (stereo lithography, etc.), use of the SLA part in hands-on verification of fit, form, and function, and then export of an IGES file to the molder or toolmaker

\section{INTRODUCTION TO ABAQUS/FEM}

The basic idea in the ABAQUS is to find the solution of complicated problem with relatively easy way. The ABAQUS/Finite Element Method has been a powerful tool for the numerical solution of a wide range of engineering problems. Applications range from deformation and stress analysis of automotive, aircraft, building, defense, and missile and bridge structures to the field of analysis of dynamics, stability, fracture mechanics, heat flux, fluid flow, magnetic flux, seepage and other flow problems. With the advances in computer technology and CAD systems, complex problems can be modeled with relative ease. Several alternate configurations can be tried out on a computer before the first prototype is built. The basics in engineering field are must to idealize the given structure for the Divide the continuum into a finite number of sub regions (or elements) of simple geometry such as required behavior. The proven knowledge in the typical problem area, modeling techniques, data transfer and integration, computational aspects of the ABQUS/Finite Element Method is essential. In this Method the solution region is considered as built up many small, interconnected sub regions called finite elements.

Most often it is not possible to ascertain the behavior of complex continuous systems without some sort of approximations. For simple members like uniform beams, plates etc., classical solutions like machine tool frames, pressure vessels, automobile bodies, ships, air craft structures, domes etc., need some approximate treatment to arrive at their behavior, be it static deformation, dynamic properties or heat conducting property. Indeed these are continuous systems with their mass and elasticity being continuously distributed. To overcome this, engineers and mathematicians have from time to time proposed complex structure is defined using a finite number of well defined components. Such systems are then regarded as discrete systems. The Discretization method could be finite difference approximation, various residual procedures etc.

\section{Steps Involved in ABAQUS/FEM:}

The method is based on stiffness analysis. Stiffness is defined as the force required for unit displacement and is reciprocal of flexibility, in this method the structure is assumed to built up of numerous connected tiny elements. From this comes the name finite element method. Extremely complex structures also can be simulated by proper arrangement of these elements.

ABAQUS/FEM allows accurate modeling through the use of variety of beam plate and solid elements simultaneously. The method being essentially convergent in nature of solutions of engineering accuracy can easily be expected. The broad steps in the FEM/ABAQUS when it is applied to structural mechanics are as follows 
line segments, triangles, quadrilaterals. (Square and rectangular elements are subset of quadrilateral), tetrahedrons and hexahedrons (cubes) etc.

Select key points on the elements to serve as nodes where conditions of equilibrium and compatibility are to be enforced.

Assume displacement functions within each element so that the displacements at each generic point are depending upon nodal values. Satisfy strain displacement and stress - strain relationships within a typical element

Determine stiffness and equivalent nodal loads for a typical element using work or energy principles.

Develop equilibrium equations for the nodes of the discredited continuum in terms of the element contributions

\section{CATIA Model of Front rear wheel differential Crown Wheel of TAURUS TIPPER}

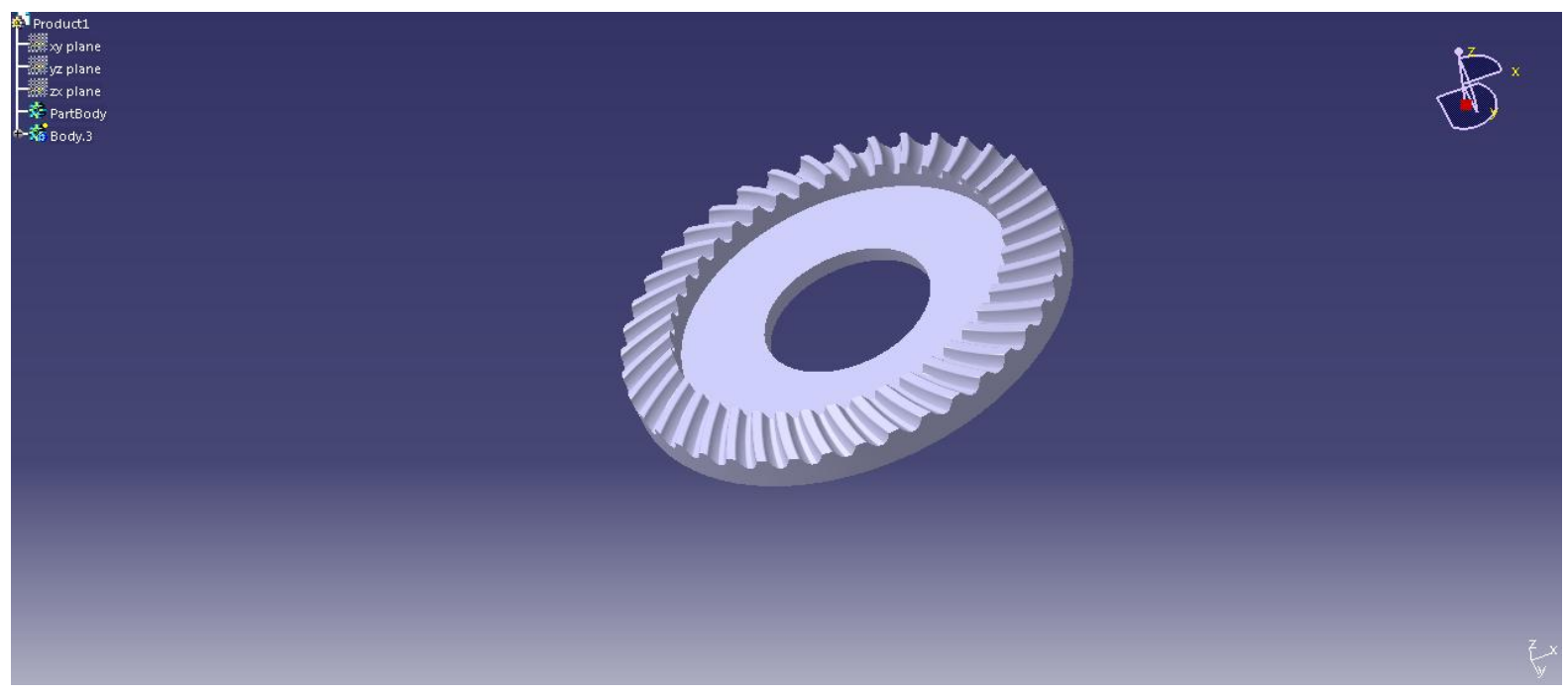

\section{RESULTS AND DISCUSSIONS}

STATIC ANALYSIS OF FRONT CROWN GEAR TEETH

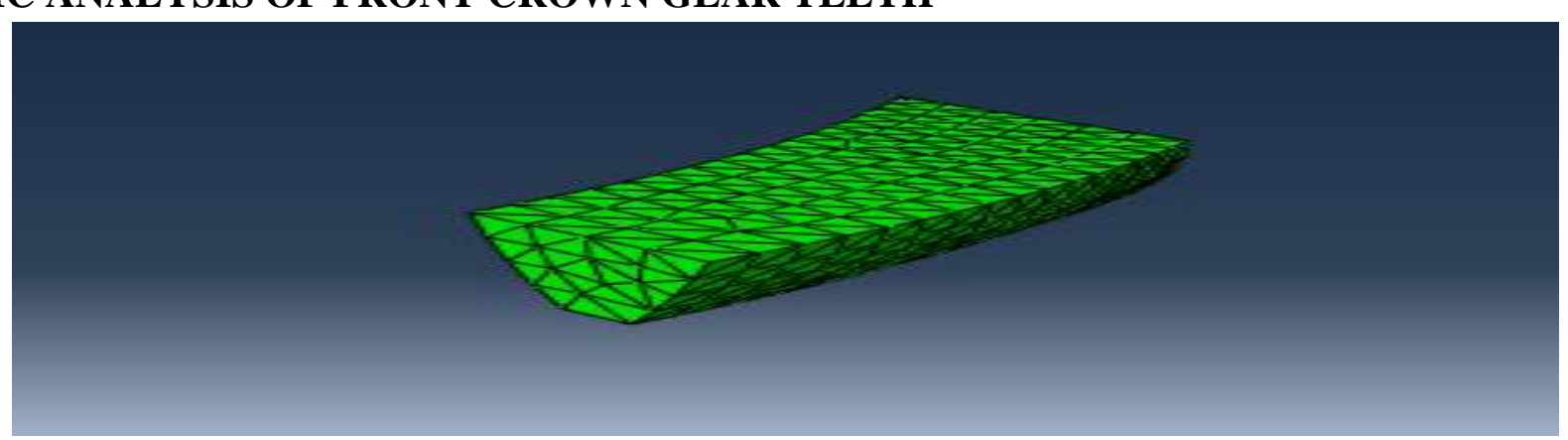

Basic meshing teeth of front rear crown wheel of differential

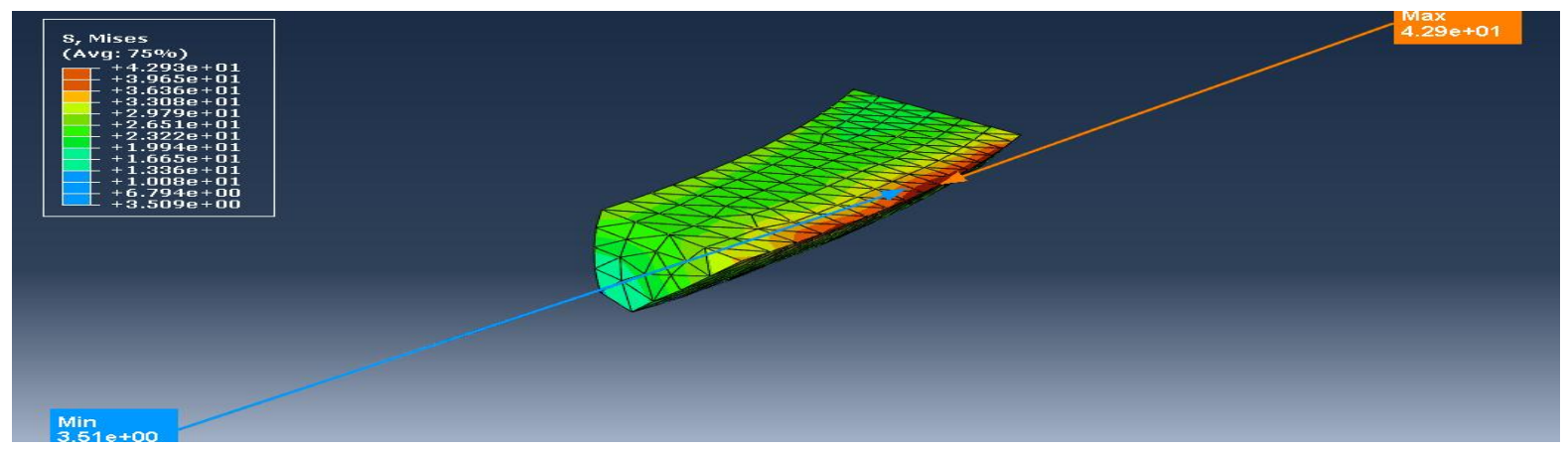




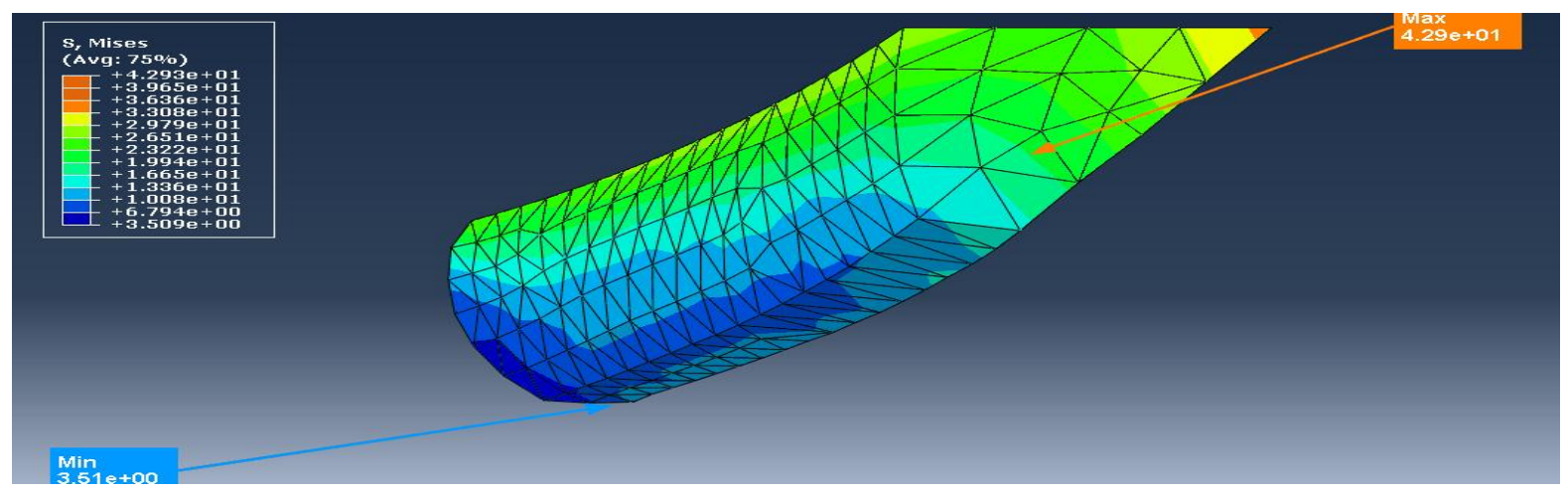

b) Von misses stresses

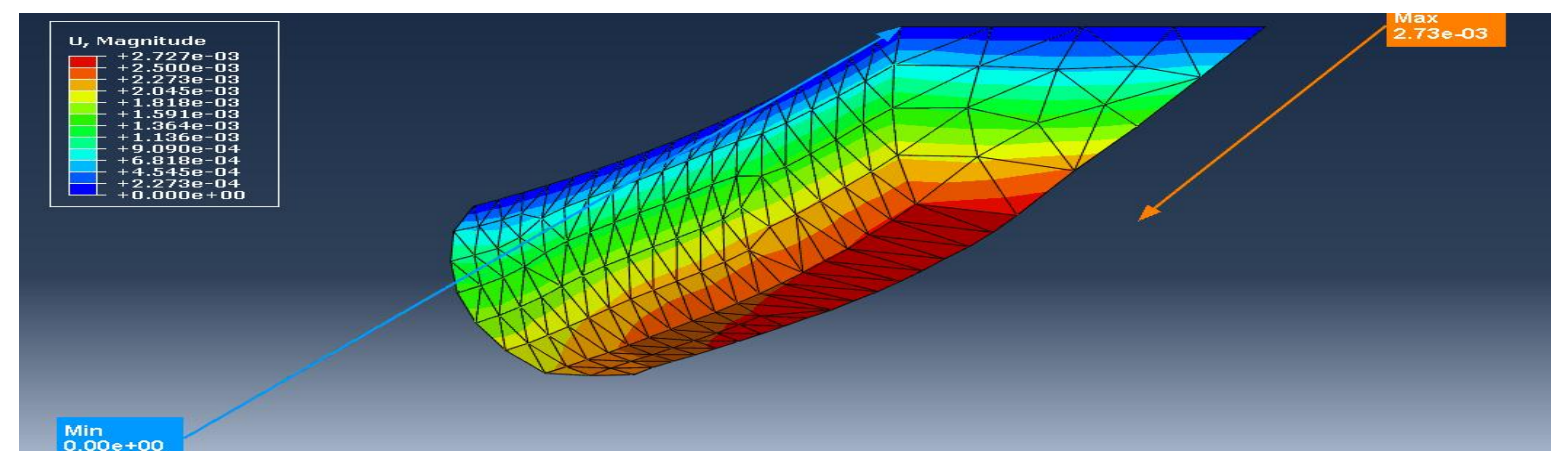

c) deformations

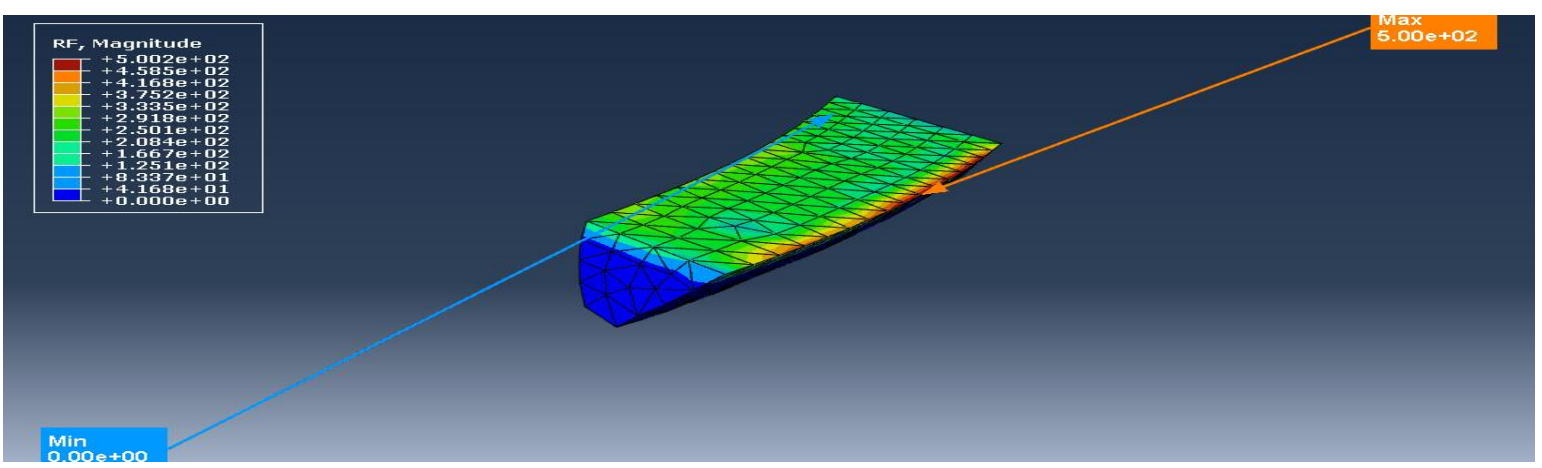

d) Reaction forces

\section{RESULTS OF FRONT CROWN TEETH OF THE DIFFERENTIAL (WITH 41 TEETH)}

\begin{tabular}{|l|l|l|l|l|l|}
\hline S.NO & MATERIAL & PROPERTIES & $\begin{array}{l}\text { MAX VON } \\
\text { MISSES } \\
\text { STRESS }\end{array}$ & $\begin{array}{l}\text { MAX } \\
\text { DEFORMATION }\end{array}$ & $\begin{array}{l}\text { MAX.REAC } \\
\text { TION } \\
\text { FORCES }\end{array}$ \\
\hline 1 & G-45 STEEL & $\begin{array}{l}\text { E=2.2X10 } \mathrm{N}^{\mathrm{N}} / \mathrm{mm}^{2} \\
\text { Poissions Ratio:0.3, } \\
\text { Load=22.16KN, } \\
\text { Surface } \\
\text { Area=1166.586. } \\
\text { Pressure }=19 . \mathrm{N} / \mathrm{mm}^{2}\end{array}$ & $42.93 \mathrm{~N} / \mathrm{mm}^{2}$ & $0.02727 \mathrm{~mm}$ & $500 \mathrm{~N}$ \\
\hline
\end{tabular}




\section{CONCLUSSIONS}

The above calculated stress of front crown wheel teeth is $42.93 \mathrm{~N} / \mathrm{mm}^{2}$, deformation is $0.02727 \mathrm{~mm}$, and Reaction force on each tooth is $500 \mathrm{~N}$. These stresses values are is less than $52 \mathrm{~N} / \mathrm{mm}^{2}$ and deformations are very less which was $0.02727 \mathrm{~mm}$ and reaction forces on each tooth is $500 \mathrm{~N}$ only. Therefore design is safe in conditions.

\section{REFERENCES:}

1. Power Transmission and Gearing Papers, On the Kinematics of the Closed Epicyclic Differential Gears,R. J. Willis, $[+]$ Author and Article Information,J. Mech. Des. 104(4), 71271(Oct01,1982)(8pages)doi:10.1115/1.325 6415History: Received June 18,1981; Online November 17, 2009

2. Case Study: Effect of Core Hardness on Impact Strength of the Crown Wheel,Paper \#:2014-28-0003 Published:2014-04-28,DOI:10.4271/201428-0003,Citation:Rao, Y.,"Case Study: Effect of Core Hardness on Impact Strength of the Crown Wheel," SAE Technical Paper 2014-28-0003, 2014,doi:10.4271/2014-28-0003.

3. DeltonBooks,http://www.deltonbooks.com ,Design and Analysis of Spiral Bevel Pinion for Bolero Pickup Differential Gear Box,Mr. Santosh S Bagewadi, Dr. S. N. Kurbet \& Prof.I.G.Bhavi B.L.D.E.A'S P.G.H College of Engg \& Technology, Bijapur,Basaveshwar Engineering College, Bagalkot

4. RESEARCH PAPERS,A Method for Thermal Analysis of Spiral Bevel Gears,R.F. Handschuh and T. P. Kicher, $[+]$ Author and Article Information,J. Mech. Des. 118(4), 580585(Dec,01,1996)(6pages)doi:10.1115/1.2 826932History: Received, May 01, 1995; Revised May 01, 1996; Online December 11, 2007.
5. PRATIK PATEL was done project on design and analysis of single differential gear box in 2009 at GANPT UNIVERSITY, KHERVA in which he was concentrated only design of shafts and bearings he should not done analysis in the differential gear box

6. Comments on "Power transmitted through a particular branch in mechanisms comprising planetary gear trains and other fixed or variable transmissions" G. Mantriota Dipartimento di Meccanica, Matematica e Management, Politecnico di Bari, Viale Japigia, 182, 70126 Bari, Italy

7. Design And Analysis Of Automobile Central Differential Having Two Different Side Gear by Amir Khan and Sankalp Verma Department of Mechanical Engineering, Shri shankaracharya institute of technology,bhilai, Chhattisgarh , India 8. Design and Structural Analysis of Differential Gear Box at Different Loads by C.Veeranjaneyulu and U. Hari Babu Address for Correspondence Department of Mechanical Engineering, QIS College of Engineering \& Technology, Ongole, and Andhra Pradesh. IJAERS/Vol. I/ Issue II/January-March, 2012/65-69

8. IOSR Journal of Mechanical and Civil Engineering (IOSR-JMCE) ISSN(e) : 2278-1684, ISSN(p) : 2320-334X, PP : 59-66 www.iosrjournals.org Design, Manufacturing \& Analysis of Differential Crown Gear and Pinion for MFWD Axle by S. H. Gawande, S.V. Khandagale, V. T. Jadhav, V. D. Patil, D. J. Thorat (Department of Mechanical Engineering, M.E.S. College of Engineering, Pune, India) 